\title{
Acute impact of left ventricular unloading by left ventricular assist device on the right ventricle geometry and function: Effect of nitric oxide inhalation
}

\author{
Marian Kukucka, MD, ${ }^{a}$ Evgenij Potapov, MD, PhD, ${ }^{\mathrm{b}}$ Alexander Stepanenko, MD, ${ }^{\mathrm{b}}$ Karsten Weller, MD, ${ }^{\mathrm{a}}$ \\ Alexander Mladenow, MD, ${ }^{\mathrm{a}}$ Hermann Kuppe, $\mathrm{MD}, \mathrm{PhD},{ }^{\mathrm{a}}$ and Helmut Habazettl, $\mathrm{MD}, \mathrm{PhD}^{\mathrm{c}}$
}

\begin{abstract}
Objective: Left ventricular assist device (LVAD) implantation is an established option for treatment of patients with end-stage heart failure, but outcome may be worsened by right ventricular failure. The aim of this study was to evaluate the acute effect of LVAD on right ventricular geometry and function and the pulmonary circulation. The effect of inhaled nitric oxide (iNO) was assessed.
\end{abstract}

\begin{abstract}
Methods: We evaluated pre- and postoperatively obtained transesophageal echocardiography images and hemodynamics of patients participating in a randomized trial on the effect of inhaled nitric oxide during LVAD implantation. Twenty-four patients were randomized to the iNO group and 23 to the placebo group.
\end{abstract}

\begin{abstract}
Results: After LVAD implantation marked decreases in pulmonary capillary wedge pressure $(P<.01)$ and mean pulmonary artery pressure $(P<.01)$ were observed in both groups. Pulmonary vascular resistance decreased only in the iNO group $(311 \pm 35$ to $225 \pm 17, P<.01)$. Transesophageal echocardiography measurements show significant improvement of right ventricular geometry (right ventricular end-diastolic diameter: $50 \pm 2$ to $45 \pm 2$, $P<.01$ and $48 \pm 2$ to $44 \pm 2 \mathrm{~mm}, P<.05$ in iNO and placebo groups) and function (right ventricular fractional area change: $24 \% \pm 2 \%$ to $31 \% \pm 2 \%, P<.05$ and $23 \% \pm 2 \%$ to $29 \% \pm 2 \%, P<.05$ in iNO and placebo groups) without any difference between the iNO and placebo groups. The overall incidence of postoperative right ventricular failure was 4 of $47(8.5 \%)$.
\end{abstract}

Conclusions: LVAD implantation markedly improved right ventricular geometry and function in most of the patients, probably by resolving left ventricular congestion and thus reducing right ventricular afterload. Beneficial effects of iNO may have been masked by more pronounced consequences of left ventricular unloading on right ventricular function. (J Thorac Cardiovasc Surg 2011;141:1009-14)

Ventricular assist device is a well established and effective therapy in patients with end-stage heart failure. ${ }^{1}$ Mechanical support improves hemodynamics, organ function, quality of life, and survival. Isolated left ventricular assist device (LVAD) implantation is preferred because of better quality of life and better risk/benefit ratio. ${ }^{2}$

The main complication in these patients is right ventricular failure (RVF), which is reported in $17 \%$ to $39 \%$ of cases. $^{3-8}$ RVF may result in compromised LVAD flow, reduced tissue perfusion, and multiorgan dysfunction, all of which are associated with a significant increase in overall morbidity and mortality.

\footnotetext{
From the Department of Anaesthesiology, ${ }^{\mathrm{a}}$ and Department of Cardiothoracic and Vascular Surgery, ${ }^{\mathrm{b}}$ Deutsches Herzzentrum Berlin, Germany; and the Institute of Physiology, ${ }^{\mathrm{c}}$ Charité Campus Benjamin Franklin, Berlin, Germany. This study was sponsored by Ikaria Holdings, Inc.

Disclosures: Authors have nothing to disclose with regard to commercial support.

Received for publication May 18, 2010; revisions received July 12, 2010; accepted for publication Aug 1, 2010; available ahead of print Sept 30, 2010.

Address for reprints: Marian Kukucka, MD, Deutsches Herzzentrum Berlin, Department of Anesthesiology, Augustenburger Platz 1, 13353 Berlin, Germany (E-mail: kukucka@dhzb.de).

$0022-5223 / \$ 36.00$

Copyright (C) 2011 by The American Association for Thoracic Surgery

doi:10.1016/j.jtcvs.2010.08.010
}

The preoperative selection of patients for LVAD or biventricular assist device (BiVAD) implantation is crucial and can improve patient outcome. Diverse scoring systems have been developed to predict $\mathrm{RVF}^{4,6,8}$ In our institution, patients are selected for LVAD implantation according to tricuspid regurgitation, right ventricular (RV) geometry in transthoracic echocardiography, and mean pulmonary pressure, ${ }^{8}$ which results in an incidence of RVF after LVAD implantation of about $10 \%$ to $12 \%$ (unpublished data).

The acute impact of LVAD on RV function in patients with end stage heart failure (HF) is not well characterized. Theoretically, the RV may benefit from a reduction of left atrial pressure. On the other hand, leftward ventricular septal shift and increased venous return induced by LVAD is identified to impair RV function. ${ }^{9,10}$ Thus, the first aim of this study was to characterize in detail the acute impact of LVAD implantation on RV geometry and function and on hemodynamics.

Patients with severe postoperative RV dysfunction require prolonged pharmacological support and in some cases additional RV assist device implantation. Clinical outcome of these patients is reported to be worse in comparison with patients scheduled for primary BiVAD implantation. ${ }^{11}$ 


\author{
Abbreviations and Acronyms \\ BiVAD $=$ biventricular assist device \\ $\mathrm{EF}=$ ejection fraction \\ FAC $=$ fractional area change \\ $\mathrm{HF}=$ heart failure \\ iNO = inhaled nitric oxide \\ LVAD $=$ left ventricular assist device \\ LVFRI = left ventricular pump flow rate index \\ $\mathrm{RVF}=$ right ventricular failure \\ RVOT $=$ right ventricular outflow tract \\ TAPSE $=$ tricuspid annular plane systolic \\ excursion \\ TEE $=$ transesophageal echocardiography \\ TPPG $=$ transpulmonary pressure gradient
}

Pharmacological strategies can help to ameliorate RV dysfunction and to avoid the development of RV failure. Conventional intravenous drug therapies include catecholamines, phosphodiesterase-III inhibitors, nitrates, and prostaglandins. The intravenous administration of vasodilators to reduce RV afterload is limited by inducing systemic vasodilatation and concomitant low myocardial perfusion pressure.

Inhaled nitric oxide (iNO) has been shown to be of benefit in the intraoperative management of patients with elevated pulmonary vascular resistance undergoing heart transplantation, lung transplantation, and other cardiac surgery. ${ }^{12-14}$ After LVAD implantation, iNO is frequently used prophylactically during cardiopulmonary bypass weaning to minimize the incidence and severity of postoperative RV dysfunction. ${ }^{15-18}$ The clinical benefit of this strategy, however, is still unclear. Thus, the second aim of the study was to assess the effect of iNO on RV geometry and function and on hemodynamics. To this effect, we evaluated perioperatively-obtained transesophageal echocardiography (TEE) images of patients participating in a randomized, controlled, multicenter trial on the effect of iNO on clinical outcome after LVAD implantation.

\section{MATERIALS AND METHODS}

A prospective, randomized, double-blind, multicenter, placebocontrolled trial was conducted at 8 centers in the United States and Germany between September 2003 and March 2008. For the present study, we included the Berlin subset of patients participating. The study was approved by the institutional ethics committee and all patients gave informed written consent.

Patients over 18 years of age scheduled to undergo their first LVAD placement were screened for enrollment. Patients with a pulmonary vascular resistance greater than 200 dyn $\times \mathrm{sec} \times \mathrm{cm}^{-5}$ before LVAD placement were eligible for the trial. Patients received either iNO at a concentration of $40 \mathrm{ppm}$ or placebo (an equivalent concentration of nitrogen), initiated at least 5 minutes before the first weaning attempt from cardiopulmonary bypass (CPB) and continued until the patient: (1) was extubated; (2) developed RV failure; or (3) was treated for 48 hours, whichever came first.
Patients had the option to cross over to open-label iNO immediately and remain on iNO for up to 14 days, if they: (1) failed to wean at least once from $\mathrm{CPB}$ due to hemodynamic failure, (2) still required pulmonary vasodilator support at the 48-hour point, or (3) met the predefined RV failure criteria.

$\mathrm{RV}$ failure was defined by the occurrence of two of the following criteria in the absence of cardiac tamponade within the first 48 hours after surgery: mean arterial pressure less than $55 \mathrm{~mm} \mathrm{Hg}$; central venous pressure greater than $16 \mathrm{~mm} \mathrm{Hg}$; mixed venous saturation less than $55 \%$; cardiac index greater than $2 \mathrm{~L} \times \min ^{-1} \times \mathrm{m}^{-2}$; inotropic support greater than 20 units. The inotropic score was calculated as described previously. ${ }^{19}$

Blinded INOvent delivery systems (Ikaria, Clinton, NJ) were used for this study.

The target of the hemodynamic management after $\mathrm{CPB}$ weaning was to achieve a cardiac index of greater than $2 \mathrm{~L} \times \mathrm{min}^{-1} \times \mathrm{m}^{-2}$, a mixed venous saturation greater than $55 \%$ and an appropriate balance between the RV and supported LV to avoid excessive LV unloading and the resulting geometrical disadvantage for the RV. Interventricular balance was monitored by TEE and an end-diastolic middle position of the ventricular septum in the 4-chamber view was considered optimum.

\section{Echocardiography}

According to recommendations of the American Society of Echocardiography (ASE), standard TEE views for assessment of LV and RV function were acquired and digitally stored (Vivid 7, Vivid I; GE Vingmed Ultrasound, Horten, Norway) immediately preoperatively after induction of anesthesia and after skin suture, both during periods of hemodynamic steady state.

To assess RV inflow tract we acquired the midesophageal 4-chamber view (ME 4C). We changed the multiplane angle from approximately $0^{\circ}$ to $20^{\circ}$ to maximize the obtainable RV size. The RV outflow tract (RVOT) was assessed from the midesophageal position in the RV inflowoutflow view.

For LV geometric measurements we used the transgastric two-chamber view (TG 2C) of the LV, usually best imaged at an angle of approximately $90^{\circ}$ to $110^{\circ}$ after optimizing for the maximum obtainable LV size.

A retrospective analysis of intraoperative echocardiographic data was carried out by an experienced echo cardiographer who was blinded to outcome parameters using an Echopac work station (Echopac, GE Vingmed Ultrasound, Horten, Norway).

For assessment of RV geometry, RV function and LV geometry parameters recommended for chamber quantification by the ASE were used. ${ }^{20}$ To quantify RV size, basal (RVEDD 1), midcavity (RVEDD 2), and maximal (RVEDD max) short axis diameters at end-diastole were measured. In addition, RV longitudinal diameter (RVEDD 3) was obtained. For quantification of RVOT from the midesophageal RV inflow-outflow view we measured the diameters at the subpulmonary region (RVOT 1) and at the pulmonary valve annulus (RVOT 2). The end-diastolic and end-systolic distances between the lateral tricuspid valve annulus and the anterior annulus of the pulmonary valve were obtained for volume calculation. $^{21}$

For assessment of RV function the RV fractional area change from end-diastolic and end-systolic areas measured in the ME 4C view was calculated. Additional assessment of the RV systolic function included measurement of tricuspid annular plane systolic excursion (TAPSE) from ME 4C view using M-mode. For volumetric calculation of RV ejection fraction a modified area length method was applied, using the areas from ME 4C view and length from RV inflow outflow view. ${ }^{21}$

LV loading was quantified by the short-axis diameter at end diastole (LVEDD) from the TG $2 \mathrm{C}$ view of the LV. The diameter was measured from the endocardium of the inferior wall to the endocardium of the anterior wall in a line perpendicular to the long axis of the ventricle at the junction of the basal and middle thirds of the long axis. To assess the interdependence between RV and LV the ratio of RVEDD max to LVEDD $(\mathrm{R} / \mathrm{L}$ ratio) was calculated. 


\section{Hemodynamic Monitoring}

Mean arterial pressure, mean pulmonary pressure, pulmonary arterial wedge pressure, central venous pressure, and cardiac output were measured after induction of anesthesia, after chest closure, and 6 hours postoperatively. Transpulmonary pressure gradient was calculated as mean pulmonary pressure minus pulmonary arterial wedge pressure. Cardiac index and pulmonary vascular resistance were calculated according to standard formulae.

\section{Clinical Outcome}

Although this study was not powered for clinical outcome, duration of mechanical ventilation, intensive care unit (ICU) stay, 30-day mortality, inotropic score, and the incidence of RV failure were assessed.

\section{Statistical Analysis}

The impact of LVAD implantation on echocardiographic and hemodynamic variables and the additional effect of iNO were evaluated by twoway repeated measures ANOVA followed by Holm-Sidak post-hoc tests. Patient characteristics and outcome data were compared between groups by Mann-Whitney rank sum test for continuous data and by Fisher's exact test for dichotomous data.

\section{RESULTS}

Forty-seven patients received complete preoperative and postoperative TEE exams and were included in the analysis. Twenty-four patients were randomized to the iNO group. Twenty-three patients were randomized to the placebo group.

Table 1 shows the clinical characteristics of the patients. There was no significant difference among groups with regard to sex distribution, body mass index, origin of cardiomyopathy, prevalence of mitral regurgitation, and right ventricular pacing.

Table 2 shows the numbers and types of devices employed in patients. All LVADs were continuous-flow devices. Most frequently implanted axial pumps included Berlin Heart Incor $(\mathrm{n}=31,7 \%)$ and HeartMate II $(\mathrm{n}=13,3 \%)$.

\section{Hemodynamic Data}

Table 3 shows the hemodynamic changes immediately and 6 hours after LVAD implantation in both groups. Pul-

TABLE 1. Patient characteristics

\begin{tabular}{lccc}
\hline & iNO & Placebo & $\boldsymbol{P}$ \\
\hline $\mathrm{N}$ & 24 & 23 & \\
DCM/ICM & $15 / 9$ & $17 / 6$ & .53 \\
Male/female & $20 / 4$ & $21 / 2$ & .67 \\
Age $(\mathrm{y})$ & $56 \pm 10$ & $53 \pm 13$ & .59 \\
BMI $\left(\mathrm{kg} / \mathrm{m}^{2}\right)$ & $27.5 \pm 4.2$ & $26.5 \pm 4.2$ & .51 \\
MI & $1.4 \pm 0.9$ & $1.4 \pm 0.8$ & .67 \\
RV-pacing $(\%)$ & $4(17)$ & $4(17)$ & 1.0 \\
ICD $(\%)$ & $12(50)$ & $11(49)$ & 1.0 \\
\hline BMI, Body
\end{tabular}

BMI, Body mass index; $D C M$, dilatative cardiomyopathy; $I C D$, internal cardiac defibrillator; $I C M$, ischemic cardiomyopathy; $M I$, mitral valve insufficiency classification. Rates or means \pm standard deviation are given.
TABLE 2. Number and type of LVAD used in LVAD groups

\begin{tabular}{llcc}
\hline \multicolumn{1}{c}{ Pump type } & Flow type & iNO & Placebo \\
\hline Berlin Heart Incor & Axial & 16 & 15 \\
HeartMate II & Axial & 6 & 7 \\
DuraHeart & Centrifugal & 2 & \\
Ventrassist & Centrifugal & & 1 \\
Total & & 24 & 23 \\
\hline iNO, Inhaled nitric oxide; $L V A D$, left ventricular assist device. Type of flow is indi- \\
cated.
\end{tabular}

monary capillary wedge pressure and mean pulmonary artery pressure decreased markedly in both groups without difference between iNO and placebo therapy. The transpulmonary pressure gradient remained unchanged. Cardiac index improved significantly in both groups. Calculated pulmonary vascular resistance decreased significantly in the iNO group but not in placebo group. Central venous pressure remained unchanged in both groups.

\section{Echocardiographic Data}

Table 4 shows the echocardiography data describing RV and LV geometry and RV function immediately before and after LVAD implantation. Comparison of geometrical data reveals acute improvement of RV end-diastolic geometry by LVAD implantation via decreases in RV annular diameter (RVEDD 1), maximal RV inflow diameter (RVEDD max), RV long axis diameter (RVEDD 3), and RV end-diastolic area. RV functional data show marked increases in fractional area change (FAC) and ejection fraction (EF). There was no significant difference between groups. RV functional improvement as assessed by changes in FAC and EF was most pronounced in patients with severely impaired preoperative RF function (Figure 1).

\section{Clinical Outcome}

In-hospital clinical outcome (Table 5) assessed as inotropic equivalent index, ventilation in hours, ICU stay in days, incidence of RV dysfunction and 30-day mortality shows no difference between groups. Overall incidence of RV failure was $8.5 \%(4 / 47)$.

Three patients in iNO group and one patient in placebo group developing RVF presented with different clinical problems. One feature common in all patients were larger than average RV and smaller than average LV preoperatively (R/L ratios $0.97 / 0.94 / 0.91$ and 0.74 to compare with mean for all patients of 0.68 ). This higher $\mathrm{R} / \mathrm{L}$ ratio may indicate severe reduced $\mathrm{RV}$ function and disturbed ventricular interdependence.

One patient presented preoperatively with the lowest CI and the highest PVR of both groups.

One patient received first day postoperatively excessive transfusion because of intra-abdominal bleeding and hemorrhagic shock. 
TABLE 3. Hemodynamic data

\begin{tabular}{|c|c|c|c|c|}
\hline & Group & Pre-OP & Post-OP & 6 Hours post-OP \\
\hline \multirow[t]{2}{*}{ MAP (mm Hg) } & NO & $71 \pm 3$ & $72 \pm 2$ & $74 \pm 2$ \\
\hline & Placebo & $69 \pm 3$ & $71 \pm 3$ & $72 \pm 2$ \\
\hline \multirow[t]{2}{*}{ MPAP (mm Hg) } & NO & $31.8 \pm 2.4$ & $24.2 \pm 1.3 \dagger$ & $23.5 \pm 1.5 \dagger$ \\
\hline & Placebo & $32.7 \pm 2.5$ & $24.2 \pm 1.9 \dagger$ & $26.6 \pm 1.8 \dagger$ \\
\hline \multirow[t]{2}{*}{ CVP (mm Hg) } & NO & $10.3 \pm 1.3$ & $8.5 \pm 3.2$ & $10.0 \pm 3.2$ \\
\hline & Placebo & $10.5 \pm 1.1$ & $9.3 \pm 1.1$ & $10.2 \pm 0.7$ \\
\hline \multirow[t]{2}{*}{ PCWP (mm Hg) } & NO & $18.2 \pm 1.7$ & $10.4 \pm 0.9 \dagger$ & $11.2 \pm 0.9 \dagger$ \\
\hline & Placebo & $18.0 \pm 1.6$ & $9.3 \pm 1.2 \dagger$ & $9.1 \pm 1.0 \dagger$ \\
\hline \multirow[t]{2}{*}{ TPPG (mm Hg) } & NO & $13.2 \pm 1.2$ & $13.8 \pm 1.0$ & $12.4 \pm 1.2$ \\
\hline & Placebo & $14.8 \pm 1.3$ & $15.0 \pm 1.3$ & $17.6 \pm 1.5$ \\
\hline \multirow[t]{2}{*}{$\operatorname{PVR}\left(\right.$ dyn $\left.\times \mathrm{s} \times \mathrm{cm}^{-5}\right)$} & NO & $311 \pm 35$ & $225 \pm 17 \dagger$ & $205 \pm 23^{*}$ \\
\hline & Placebo & $298 \pm 26$ & $234 \pm 23$ & $274 \pm 30$ \\
\hline \multirow[t]{2}{*}{$\mathrm{CI}\left(\mathrm{L} \times \mathrm{m}^{-1} \times \mathrm{m}^{-2}\right)$} & NO & $1.94 \pm 0.09$ & $2.61 \pm 0.13 \dagger$ & $2.67 \pm 0.12 \dagger$ \\
\hline & Placebo & $2.19 \pm 0.12$ & $2.53 \pm 0.08^{*}$ & $2.64 \pm 0.08 \dagger$ \\
\hline \multirow[t]{2}{*}{$\mathrm{SvO}_{2}(\%)$} & NO & $71 \pm 2$ & $76 \pm 2$ & $74 \pm 3$ \\
\hline & Placebo & $69 \pm 3$ & $74 \pm 2$ & $74 \pm 2$ \\
\hline \multirow[t]{2}{*}{$\operatorname{LVFRI}\left(\mathrm{L} \times \mathrm{m}^{-1} \times \mathrm{m}^{-2}\right)$} & NO & & $2.55 \pm 0.14$ & $2.58 \pm 0.09$ \\
\hline & Placebo & & $2.44 \pm 0.07$ & $2.53 \pm 0.07$ \\
\hline
\end{tabular}

$\overline{C I}$, Cardiac index; $C V P$, central venous pressure; $L V F R I$, left ventricular pump flow rate index; $M A P$, mean arterial pressure; $M P A P$, mean pulmonary artery pressure; $N O$, nitric oxide; $P C W P$, pulmonary capillary wedge pressure; $P V R$, pulmonary vascular resistance; $\mathrm{SvO}_{2}$, mixed venous oxygen saturation; $T P P G$, transpulmonary pressure gradient. Means \pm standard error of the mean. $* P<.05 . \dagger P<.01$ versus Pre-OP by 2 -way RM analysis of variance; post-hoc, Holm-Sidak.

\section{DISCUSSION}

The main finding of our perioperative TEE study is a marked immediate improvement of RV geometry and function after implantation of LVAD that seems to result from the relief of LV congestion as assessed by PCWP and the concomitant reduction in RV afterload. iNO, although decreasing pulmonary vascular resistance, had no additional beneficial effect on RV geometry and function.

Despite the high incidence of RVF after implantation of LVAD, few previous studies have focused on its acute effects on RV geometry and function.

In 1993, Holman et $\mathrm{al}^{10}$ described the acute worsening of tricuspid regurgitation after LVAD implantation. They identified leftward displacement of the ventricular septum as the presumable cause of RV dysfunction. This notion is confirmed by experimental data suggesting that during LVAD support, RV function may worsen despite the reduction of pulmonary venous pressure by unloading of LV due to an altered systolic ventricular interaction as a result of the change in LV/RV geometry. ${ }^{22}$

At present, intraoperative TEE is used for therapy guiding during LVAD implantation. ${ }^{23}$ One of the main goals during TEE monitoring immediately after $\mathrm{CPB}$ weaning in our patients is the early recognition and therapy of severe ventricular septum shift toward the left after LVAD implantation. We recognize as an optimal balance between $\mathrm{RV}$ and LV loading the middle position of the ventricular septum in the $4 \mathrm{C}$ view. In addition the difference between CVP and left atrial pressure (LAP) is monitored continuously as a measure of balanced RV versus LV loading.
An increasing CVP to LAP difference could be a sign of LV unloading and RV dysfunction. Therapeutic options for treatment of RV to LV dysbalance are additional pharmacological support for the RV and reduction of LVAD flow rate. With this regimen RV geometry and function improved rather than worsened in the majority of patients. Only 5 of 47 patients presented with a greater than $10 \%$ increase in RVEDDmax. Because RV loading as assessed by CVP was not altered, improved RV end-diastolic geometry seems to result from improved systolic function due to the marked reduction in RV afterload by LVAD implantation. PCWP and MPAP decreased by, respectively, $46 \%$ and $25 \%$ after LVAD implantation allowing for a $29 \%$ increase of FAC and RVEF.

More recent long-term echocardiographic evaluations after LVAD implantation also failed to show a worsening of $\mathrm{RV}$ function. Maeder et $\mathrm{al}^{24}$ reported that during continuous-flow LVAD support, pre-existing RV dysfunction did not worsen in the intermediate term.

Lam et $\mathrm{al}^{25}$ showed that RV size, RV FAC, and TAPSE did not consistently change within 6 months after LVAD implantation. However, they detected marked variability in the RV changes after implantation and demonstrated the association between clinical improvements after LVAD implantation with the echocardiographic measures of PVR and RV FAC.

Pronounced variability in acute RV responses to LVAD implantation was also noted in our study. Thus, RV FAC and $\mathrm{EF}$ improved predominantly in patients with severely reduced preoperative RV function (Figure 1). The increase in FAC or EF was not associated with the amount of 
TABLE 4. Perioperative echocardiographic data

\begin{tabular}{|c|c|c|c|}
\hline & Group & Pre-OP & Post-OP \\
\hline \multirow[t]{2}{*}{ RVEDD 1 (mm) } & NO & $41 \pm 2$ & $35 \pm 1 \dagger$ \\
\hline & Placebo & $39 \pm 2$ & $35 \pm 1 \dagger$ \\
\hline \multirow[t]{2}{*}{ RVEDD 2 (mm) } & NO & $42 \pm 2$ & $39 \pm 2$ \\
\hline & Placebo & $42 \pm 1$ & $39 \pm 2$ \\
\hline \multirow[t]{2}{*}{ RVEDD max (mm) } & NO & $50 \pm 2$ & $45 \pm 2 \dagger$ \\
\hline & Placebo & $48 \pm 2$ & $44 \pm 2 *$ \\
\hline \multirow[t]{2}{*}{ RVEDD 3 (mm) } & NO & $81 \pm 2$ & $72 \pm 2 \dagger$ \\
\hline & Placebo & $84 \pm 2$ & $73 \pm 2 \dagger$ \\
\hline \multirow[t]{2}{*}{$\mathrm{R} / \mathrm{L}$ ratio } & NO & $0.61 \pm 0.02$ & $0.85 \pm 0.05^{*}$ \\
\hline & Placebo & $0.58 \pm 0.02$ & $0.95 \pm 0.12 \dagger$ \\
\hline \multirow[t]{2}{*}{ RVOT 1 (mm) } & NO & $34 \pm 1$ & $31 \pm 1$ \\
\hline & Placebo & $32 \pm 1$ & $32 \pm 1$ \\
\hline \multirow[t]{2}{*}{ RVOT 2 (mm) } & NO & $26 \pm 1$ & $25 \pm 1$ \\
\hline & Placebo & $27 \pm 1$ & $26 \pm 1$ \\
\hline \multirow[t]{2}{*}{ LVEDD (mm) } & NO & $74 \pm 2$ & $55 \pm 2 \dagger$ \\
\hline & Placebo & $72 \pm 2$ & $54 \pm 4 \dagger$ \\
\hline \multirow[t]{2}{*}{$\operatorname{RVAD}\left(\mathrm{cm}^{2}\right)$} & NO & $23.7 \pm 1.2$ & $20.6 \pm 1.3 \dagger$ \\
\hline & Placebo & $24.5 \pm 1.2$ & $21.1 \pm 0.9 \dagger$ \\
\hline \multirow[t]{2}{*}{$\operatorname{RVAS}\left(\mathrm{cm}^{2}\right)$} & NO & $18.1 \pm 1.1$ & $14.2 \pm 1.0 \dagger$ \\
\hline & Placebo & $18.9 \pm 1.1$ & $15.0 \pm 0.8 \dagger$ \\
\hline \multirow[t]{2}{*}{ FAC $(\%)$} & NO & $23.9 \pm 2.3$ & $31.1 \pm 2.2^{*}$ \\
\hline & Placebo & $22.7 \pm 2.0$ & $28.9 \pm 2.0^{*}$ \\
\hline \multirow[t]{2}{*}{ TAPSE (mm) } & NO & $14.5 \pm 1.4$ & $13.0 \pm 1.1$ \\
\hline & Placebo & $14.4 \pm 1.3$ & $11.8 \pm 0.6$ \\
\hline \multirow[t]{2}{*}{ RVEDV (ml) } & NO & $147 \pm 9$ & $119 \pm 9 \dagger$ \\
\hline & Placebo & $152 \pm 10$ & $129 \pm 6 \dagger$ \\
\hline \multirow[t]{2}{*}{ RVESV (ml) } & NO & $99 \pm 8$ & $71 \pm 5 \dagger$ \\
\hline & Placebo & $106 \pm 8$ & $78 \pm 5 \dagger$ \\
\hline \multirow[t]{2}{*}{ RVSV (ml) } & NO & $48 \pm 3$ & $48 \pm 4$ \\
\hline & Placebo & $46 \pm 4$ & $51 \pm 3$ \\
\hline \multirow[t]{2}{*}{ RVEF (\%) } & NO & $33 \pm 2$ & $41 \pm 2 *$ \\
\hline & Placebo & $29 \pm 2$ & $39 \pm 2 \dagger$ \\
\hline
\end{tabular}

$F A C$, Fractional area change; $L V E D D$, left ventricular end-diastolic diameter; $N O$, nitric oxide; $R V A D$, right ventricular diastolic area; $R V A S$, right ventricular systolic area; $R V E D D$, right ventricular end-diastolic diameter; $R V E D V$, right ventricular end-diastolic volume; $R V E F$, right ventricular ejection fraction; RVESV, right ventricular end-systolic volume; RVOT, right ventricular outflow tract; RVSV, right ventricular stroke volume; TAPSE, tricuspidal annular plane systolic excursion. Means \pm standard error of the mean $* P<.05 . \dagger P<.01$ by 2 -way RM analysis of variance, post-hoc, Holm-Sidak

inotropic drugs $(R=0.15, P=.36$ for FAC and $R=0.10$, $P=.54$ for $\mathrm{EF})$. A less pronounced but still significant dependence on preoperative data was also detected for enddiastolic RV geometry (RVAD change versus preoperative RVAD: $R=-0.43, P=.003$ ). Obviously patients with severe preoperative RV dysfunction profited more from RV afterload reduction by LVAD than patients with better preserved RF function in whom the RV could better compensate for the increased afterload.

iNO, although decreasing PVR, had no measurable effect on RV geometry or function. By decreasing PVR, iNO might act as a prophylactic drug that decreases RV afterload and improves LV loading, thus moderating the detrimental effect of altered ventricular interaction on the RV. Decreased pulmonary artery pressure and improved pump
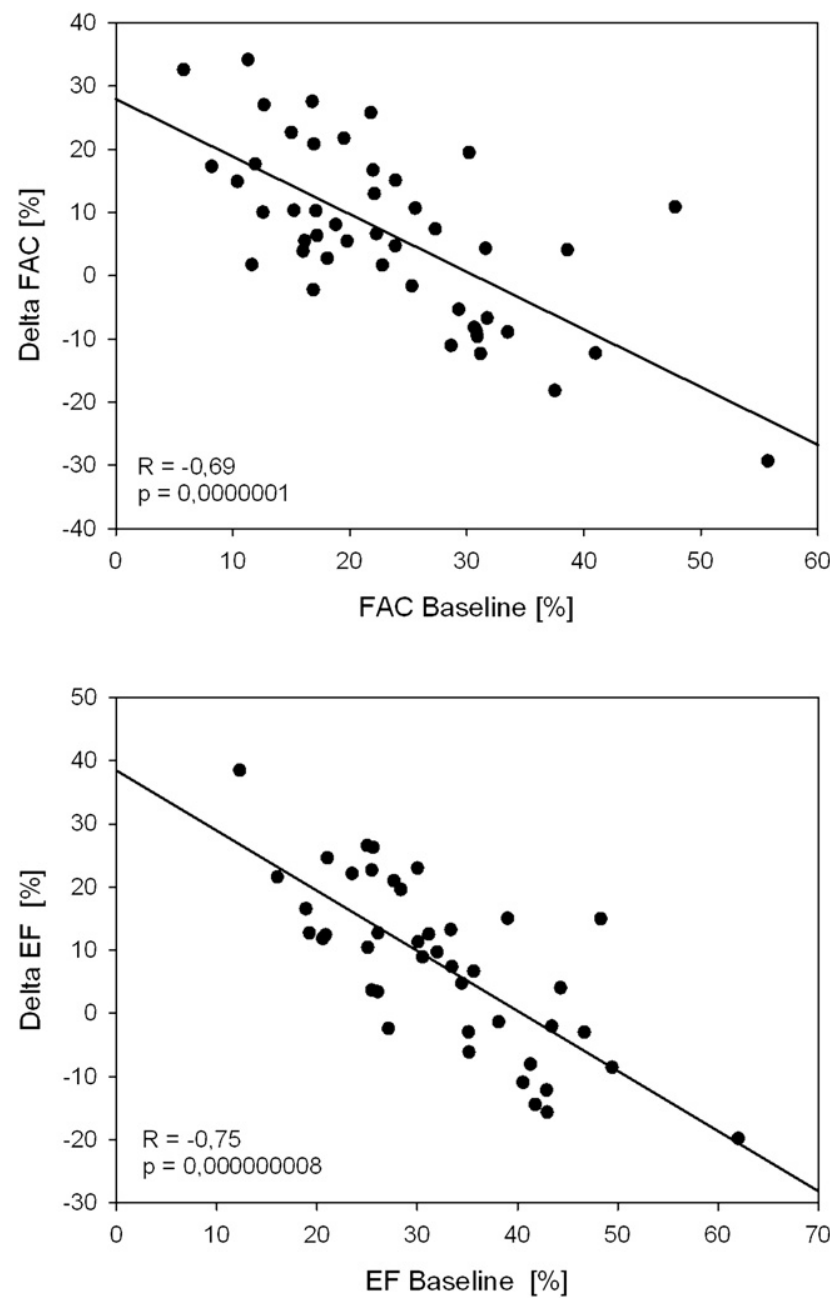

FIGURE 1. Postoperative changes of RV function ( $\Delta$ FAC and EF) depend on preoperative values. Most marked improvement was seen in patients with severely impaired preoperative function.

flow rate during postoperative NO administration after isolated LVAD implantation have been described previously. ${ }^{15}$ In this study, however, only patients with increased PVR during weaning from cardiopulmonary bypass were included. Thus a patient subgroup was selected that may profit most from pulmonary vasodilator therapy. In the present

TABLE 5. In-hospital outcome

\begin{tabular}{|c|c|c|}
\hline & NO & Placebo \\
\hline $\mathrm{N}$ & 24 & 23 \\
\hline Inotropic therapy index & $24(10 ; 32)$ & $24(14 ; 31)$ \\
\hline Ventilation (h) & $51(25 ; 334)$ & $74(28 ; 605$ \\
\hline ICU stay (d) & $17(10 ; 27)$ & $15(9 ; 40)$ \\
\hline RVF (\%) & $3(13)$ & $1(4)$ \\
\hline 30-Day mortality (\%) & $5(21)$ & $3(13)$ \\
\hline
\end{tabular}

$I C U$, Intensive care unit; $N O$, nitric oxide; $R V F$, right ventricular failure. Median ( $25 ; 75$ percentiles) or number $(\%)$. No significant differences between groups were detected. 
study, only elective patients without acute decompensation of chronic heart failure, but with increased preoperative PVR were included irrespective of the hemodynamic scenario during weaning. Thus the patients in the present study were probably less severely diseased than patients in previous studies, which showed a benefit of iNO. ${ }^{15}$ In addition, decreased PVR does not necessarily improve RV geometry and function that were not assessed in this previous study. Also the marked reduction in RV afterload by LVAD itself together with the postoperative regimen of limiting the septal shift to the left by adjusting the inotropic therapy and the LVAD flow rate may have masked potentially beneficial effects of iNO.

In accordance with the improvement of RV function seen in the majority of patients the incidence of RV failure was very low in our patient cohort (4 of 47). This may be due to our stringent selection criteria to schedule primary BiVAD implantation for patients with severe preoperative $\mathrm{RV}$ dilatation, tricuspid regurgitation, and markedly reduced RV function. ${ }^{8}$

\section{CONCLUSIONS}

In patients preselected for LVAD therapy, RV geometry and function improve markedly immediately after LVAD implantation, due to the unloading of the LV and the concomitant reduction of RV afterload. Detection of excessive $\mathrm{LV}$ unloading and distortion of normal ventricular interaction by TEE and its consecutive correction by pharmacological support and adjustment of the LVAD flow rate may be pivotal for the preservation of RV function and geometry in these patients. The use of iNO should be reserved for those patients who are most likely to benefit. This may include patients with high pulmonary artery pressure or low pump flow rate during weaning from cardiopulmonary bypass.

\section{References}

1. Rose EA, Gelijns AC, Moskowitz AJ, Heitjan DF, Stevenson LW, Dembitsky W, et al. Long-term mechanical left ventricular assistance for end-stage heart failure. N Engl J Med. 2001;345:1435-43.

2. Deng MC, Edwards LB, Hertz MI, Rowe AW, Keck BM, Kormos R, et al. Mechanical circulatory support device database of the International Society for Heart and Lung Transplantation: third annual report-2005. J Heart Lung Transplant. 2005;24:1182-7.

3. Dang NC, Topkara VK, Mercando M, Kay J, Kruger KH, Aboodi MS, et al. Right heart failure after left ventricular assist device implantation in patients with chronic congestive heart failure. J Heart Lung Transplant. 2006;25:1-6.

4. Fitzpatrick JR 3rd, Frederick JR, Hsu VM, Kozin ED, O'Hara ML, Howell E, et al. Risk score derived from pre-operative data analysis predicts the need for biventricular mechanical circulatory support. J Heart Lung Transplant. 2008; 27:1286-92.

5. Fukamachi K, McCarthy PM, Smedira NG, Vargo RL, Starling RC, Young JB. Preoperative risk factors for right ventricular failure after implantable left ventricular assist device insertion. Ann Thorac Surg. 1999;68:2181-4.
6. Matthews JC, Koelling TM, Pagani FD, Aaronson KD. The right ventricular failure risk score a pre-operative tool for assessing the risk of right ventricular failure in left ventricular assist device candidates. J Am Coll Cardiol. 2008;51:2163-72.

7. Ochiai Y, McCarthy PM, Smedira NG, Banbury MK, Navia JL, Feng J, et al. Predictors of severe right ventricular failure after implantable left ventricular assist device insertion: analysis of 245 patients. Circulation. 2002;106(Suppl 1): I198-202.

8. Potapov EV, Stepanenko A, Dandel M, Kukucka M, Lehmkuhl HB, Weng Y, et al. Tricuspid incompetence and geometry of the right ventricle as predictors of right ventricular function after implantation of a left ventricular assist device. J Heart Lung Transplant. 2008;(27):1275-81.

9. Haddad F, Couture P, Tousignant C, Denault AY. The right ventricle in cardiac surgery, a perioperative perspective: II. Pathophysiology, clinical importance, and management. Anesth Analg. 2009;108:422-33.

10. Holman WL, Bourge RC, Fan P, Kirklin JK, Pacifico AD, Nanda NC. Influence of left ventricular assist on valvular regurgitation. Circulation. 1993;88:II309-18.

11. Fitzpatrick JR 3rd, Frederick JR, Hiesinger W, Hsu VM, McCormick RC, Kozin ED, et al. Early planned institution of biventricular mechanical circulatory support results in improved outcomes compared with delayed conversion of a left ventricular assist device to a biventricular assist device. J Thorac Cardiovasc Surg. 2009; 137:971-7.

12. Solina A, Papp D, Ginsberg S, Krause T, Grubb W, Scholz P, et al. A comparison of inhaled nitric oxide and milrinone for the treatment of pulmonary hypertension in adult cardiac surgery patients. J Cardiothorac Vasc Anesth. 2000;14:12-7.

13. Schmid ER, Burki C, Engel MH, Schmidlin D, Tornic M, Seifert B. Inhaled nitric oxide versus intravenous vasodilators in severe pulmonary hypertension after cardiac surgery. Anesth Analg. 1999;89:1108-15.

14. Bender KA, Alexander JA, Enos JM, Skimming JW. Effects of inhaled nitric oxide in patients with hypoxemia and pulmonary hypertension after cardiac surgery. Am J Crit Care. 1997;6:127-31.

15. Argenziano M, Choudhri AF, Moazami N, Rose EA, Smith CR, Levin HR, et al. Randomized, double-blind trial of inhaled nitric oxide in LVAD recipients with pulmonary hypertension. Ann Thorac Surg. 1998;65:340-5.

16. Wagner F, Dandel M, Gunther G, Loebe M, Schulze-Neick I, Laucke U, et al. Nitric oxide inhalation in the treatment of right ventricular dysfunction following left ventricular assist device implantation. Circulation. 1997;96(Suppl):291-6.

17. Hare JM, Shernan SK, Body SC, Graydon E, Colucci WS, Couper GS. Influence of inhaled nitric oxide on systemic flow and ventricular filling pressure in patients receiving mechanical circulatory assistance. Circulation. 1997;95:2250-3.

18. Chang JC, Sawa Y, Ohtake S, Fukushima N, Nishimura M, Kagizaki K, et al. Hemodynamic effect of inhaled nitric oxide in dilated cardiomyopathy patients on LVAD support. ASAIO J. 1997;43:M418-21.

19. Kormos RL, Gasior TA, Kawai A, Pham SM, Murali S, Hattler BG, et al. Transplant candidate's clinical status rather than right ventricular function defines need for univentricular versus biventricular support. J Thorac Cardiovasc Surg. 1996; 111:773-82; discussion 82-3.

20. Lang RM, Bierig M, Devereux RB, Flachskampf FA, Foster E, Pellikka PA, et al. Recommendations for chamber quantification: a report from the American Society of Echocardiography's Guidelines and Standards Committee and the Chamber Quantification Writing Group, developed in conjunction with the European Association of Echocardiography, a branch of the European Society of Cardiology. J Am Soc Echocardiogr. 2005;18:1440-63.

21. Denslow S, Wiles HB. Right ventricular volumes revisited: a simple model and simple formula for echocardiographic determination. J Am Soc Echocardiogr. 1998;11:864-73.

22. Santamore WP, Dell'Italia LJ. Ventricular interdependence: significant left ventricular contributions to right ventricular systolic function. Prog Cardiovasc Dis. 1998;40:289-308.

23. Mets B. Anesthesia for left ventricular assist device placement. J Cardiothorac Vasc Anesth. 2000;14:316-26.

24. Maeder MT, Leet A, Ross A, Esmore D, Kaye DM. Changes in right ventricular function during continuous-low left ventricular assist device support. J Heart Lung Transplant. 2009;28:360-6.

25. Lam KM, Ennis S, O'Driscoll G, Solis JM, Macgillivray T, Picard MH. Observations from non-invasive measures of right heart hemodynamics in left ventricular assist device patients. J Am Soc Echocardiogr. 2009;22:1055-62. 